\title{
PECULIARITIES OF ASSESSING THE RESERVOIR PROPTIES OF CLAYISH RESERVOIRS DEPENDING ON THE WATER OF RESERVOIR PRESSURE MAINTENANCE SYSTEM PROPERTIES
}

\author{
Palyanitsina Alexandra Nikolaevna ${ }^{1 *}$, Sukhikh Alexander Sergeevich ${ }^{2}$ \\ ${ }^{1}$ Ph.D Saint-Petersburg Mining University, Russian Federation \\ ${ }^{2}$ Saint-Petersburg Mining University, Russian Federation
}

The clayish reservoirs of Western Siberia contain more than $60 \%$ of the reserves and about half of all oil resources of the Russian Federation. Traditionally, oil production from such reservoirs is accompanied by swelling of clay minerals that are part of the reservoir rock. Such minerals increase in volume when interacting with the waters of the reservoir pressure maintenance system. And this, in turn, causes the clogging of the pore channels. Kaolinite, which is part of the reservoir rock, is usually considered low-swellable clay or completely non-swellable. Therefore, when designing a reservoir pressure maintenance system and choosing a source of water for it, the possible swelling of this clay is not taken into account. Using non-destructive testing methods, the filtration-capacitance properties of clay rocks were determined before and after interaction with different types of waters, and mechanisms for reducing swelling, suitable for optimizing the reservoir pressure maintenance system, were identified.

Key words: oil production, porosity, permeability, filtration properties, water mineralization, smart water, jurassic deposits

\section{INTRODUCTION}

The clay reservoirs of Western Siberia (Russia) contain more than $2 / 3$ of the reserves and about half of all oil resources of the Russian Federation. But oil production from such reservoirs is traditionally accompanied by the fact that clay minerals increase in volume when interacting with the waters of the reservoir pressure maintenance system (RPMS), which causes the pore channels to clog.

The volumetric method has traditionally been used to determine the effect of various salinity of water or chemical components in its composition on the state of clay particles of rocks (Figure 1). But this method does not give a real picture of what is happening in the reservoir for several reasons. First, when working on this device, it is necessary to use disintegrated and dried clay powder, while clay in the formation is in a completely different state. And second, clay minerals of different types and different metamorphization can be in the reservoir, which is impossible to recreate under the conditions of using clay powder or a single piece of clay of one type. Therefore, in order to identify the behavior of clay minerals in reservoir conditions in a deformed and saturated state, it is necessary to use non-destructive testing methods.

To assess the effect of chemical compositions or formation water mineralization on the size of clay minerals that are located directly in the formation and constitute an integral part of the pore space, it is necessary to use methods that control such parameters as porosity and specific grain surface (Gimatudinov, 1971).

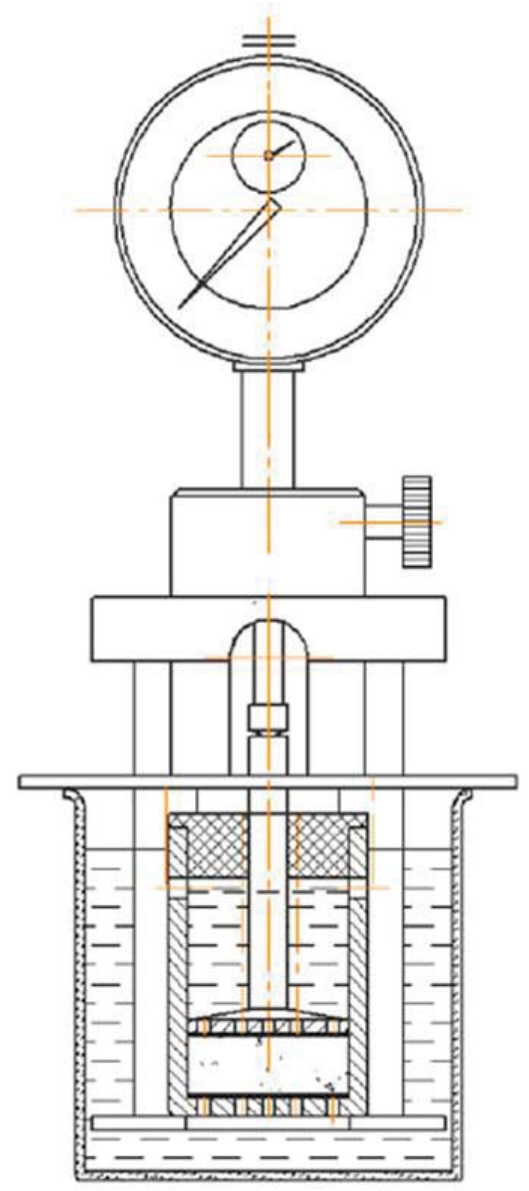

Figure 1: Standard Zhigach-Yarov device for determining clay swelling 


\section{LITERATURE REVIEW}

\section{Porosity assessment methods}

Each Chapter starts with two line be centered at the top of the page; it has to be Times New Roman.

There are several standard types of determining the porosity of a sample. The first, most classical method is the method of saturating a sample with kerosene or hydrostatic weighing. Using this method, both pore volume and sample volume can be determined. The method consists of determining the volume of kerosene saturating the pores.

The next method is to inject mercury. This method allows one to judge not only the volume of pore space but also the size distribution of pores. The pore sizes are inversely proportional to the pressure that is necessary for the injection of mercury into the core (Yemelyanov et al., 2019; Neizvestnaya et al., 2018).

This method uses precisely mercury because it is a non-wetting phase for any surfaces. This method has several disadvantages. Firstly, it is not suitable for samples with low permeability, because it is necessary to create a very high injection pressure, for the same reason, the method is limited by pore sizes. Secondly, this method, like the previous and next, shows the sizes of only open, interconnected pores. And thirdly, this method does not measure pore size but rather determines the largest pore connection between each other(I.R. Raupov, 2018), (D.V. Sun, 2018).

The next, more modern method, is a method based on the application of Boyle-Marriott's law. At a constant temperature, measure the pressure that the gas exerts when pumping into the volume of an empty core holder, the maximum filled core and the core holder inside. Thus, the volume of pore space is calculated taking into account errors.

An even more modern method is optical. The method is based on the study of the surface of a polished thin core sample. This method is the most accurate and allows you to evaluate and take into account even the smallest and most closed pores that are not available to other methods. But in our case, all of the above methods are not suitable for assessing the effect on the porosity of rock saturating fluids. The former is not accurate enough, and in preparation for the latter, the conditions created by the saturating fluid may be impaired (F. Manalo, 2001).

Methods that are suitable for research are microtomography and sorption methods. Using the first method, you can get a three-dimensional model of the sample and complete information about the structure of its pore space and the size of all pores. The disadvantages of this method can only be attributed to the fact that water saturating the reservoir rock and absorbed by clay minerals will impede the penetration of X-rays (S.C. Motta Cabrera, 2008),(J. Perret, 1998).
The final and most appropriate method is the method of measuring sorption. Since sorption begins in the smallest pores and continues in larger ones, a change in capillary pressure can be recorded. As a result, the adsorbed volume is a function of pressure at a constant temperature. The most commonly used adsorbate for these purposes is nitrogen. When determining the adsorption of vapors and gases, it is possible to obtain information on the porosity of solids and its structure and the specific surface. Depending on the surface area of the body and its porosity, solids can absorb more or less gas. Also, the amount of gas that solids can absorb depends on the properties and nature of the gas and on the material of the body itself.

\section{Features of the structure and development of low-permeable clayish reservoirs}

The main features that affect the development process of low-permeability polymictic collectors are their structure and composition. The structural features are that the pore space is characterized by a high content of pores of small diameter: sub capillary and capillary. The compositional features include the fact that both the rock-forming and cementing parts have an extremely heterogeneous composition. In particular, a large number of clay minerals are present in the composition, which can hydrate, the degree of which depends on the structure of the minerals and their type. Therefore, collectors of this type are characterized by high water retention capacity, specific surface area, and adsorption. So, in the process of their development, the main role will be played by capillary and intermolecular forces, rather than hydrodynamic ones.

The interaction of clay minerals with water causes an increase in their volume, and, accordingly, the culmination of pore channels. In the case of low-permeability polymictic reservoirs, in which most of the pores are represented by capillaries and sub capillaries, even a slight increase in the volume of clay minerals leads to a significant decrease in oil permeability. Therefore, in such deposits, it is necessary to pay increased attention to the quality of water treatment, as well as to take into account the possibility of using chemical compositions to inhibit the hydration of clay minerals (Khavkin, 2010).

\section{The influence of the reservoir pressure maintenance system on the reservoirs' properties}

The oil and gas reservoirs are characterized by the established balance between their saturating aqueous medium and clay minerals cementing the reservoir. With a change in ionic balance in the system "water - clay mineral", the main feature of clay minerals is realized - their ability to ion exchange. The dynamics of this process are determined by the mineralogical composition of clays, their specific properties, as well as the chemical composition of the injected water. That is why the right choice 
of water for the reservoir pressure maintenance system is one of the most important tasks for the effective development of oil fields.

The main promising reservoirs of Western Siberia are the Upper Jurassic and Middle Jurassic deposits. These deposits are composed of polymictic sandstones with a high clay content. Clay is represented mainly by minerals such as kaolinite, illite, hydromica.

The main promising reservoirs of Western Siberia are the Upper Jurassic and Middle Jurassic deposits. These deposits are composed of polymictic sandstones with a high clay content. Clay is represented mainly by minerals such as kaolinite, illite, hydromica.

Kaolinite $\left(\mathrm{Al}_{4}\left[\mathrm{Si}_{4} \mathrm{O}_{10}\right][\mathrm{OH}]_{8}\right)$ is a clay mineral that is part of the group of aqueous silicates. Consists of small hexagonal crystals. The crystals consist of tetrahedral sheets of silicon oxide, which have three common oxygen, and with free vertices are connected with aluminum and hydroxo groups. The sheets are weakly connected, which is why kaolinite has very perfect cleavage. As a whole, it forms earthy masses, but individual scales are hexagonal, rhombic or trigonal plates. Minerals of the kaolinite type almost do not swell in water, have low adsorption capacity and low absorption capacity. But during the flooding of low-permeability formations, even lowswellable chlorites, hydromica and kaolinites will have a significant effect.

For the system of maintaining reservoir pressure in Western Siberia, water from aquifers (Cenomanian deposits), as well as freshwater from open reservoirs are actively used. Research (A.N. Kuznetsova, 2018) showed that as a result of interaction with less mineralized waters, such as Cenomanian or fresh, clay particles swell, even the kaolin type.

Clay minerals can change pore space, due to their ability to swell and metamorphize. The increased clay volume can both remain on the skeleton of the rock and break away from it, leading to the dispersion of clays. These processes are possible due to the ion exchange characteristic of clay minerals, as well as the absorption of water from the pore space - its adsorption. Thus, as a result of clay swelling, the permeability of the reservoir can be reduced tenfold (Khanin, 1969), (Khavkin, 2010).

The resource of mineralized formation water is limited, therefore, it is economically feasible to continue to use low salinity water — fresh or Cenomanian — in fields for a system for maintaining reservoir pressure. It should also be borne in mind that the injection of mineralized water, even close in composition to the formation, can lead to the interaction of water with each other and the formation of poorly soluble sediment in the pore space in the form of new phases, for example, gypsum, which can further reduce the filtration-capacitive properties (FES) developed strata. Thus, for low-permeability clayish reservoirs, improving the existing waterflooding system becomes a priority.
From this, we can conclude that the water purification system for injection into low-permeability clayed formations to maintain reservoir pressure, used in most oil fields, is not effective enough and should be improved through the introduction of new, modern equipment that will allow fresh water to be purified to the required conditions. Also, it is possible to increase the efficiency of the reservoir pressure maintenance system by changing the properties of the injected water, namely by adding surfactants, because surfactants, in addition to the known ability to reduce interfacial tension at the oil-water interface, are also able to inhibit clay swelling. And this will allow the use of fresh and desalinated water for flooding low-permeable clayish reservoirs without the threat of clogging.

\section{EXPERIMENT METHODS}

The International Union of Pure and Applied Chemistry (IUPAC) has approved pore size classification, which is expressed in adsorption isotherms corresponding to the characteristic adsorption properties for each pore size range. According to this classification, micropores are pores whose size is less than $2 \mathrm{~nm}$; macropores - more than $50 \mathrm{~nm}$; pores with sizes from 2 to $50 \mathrm{~nm}$ are called mesopores (Volkov, 2001).

Adsorption processes occurring in pores of different sizes are also different. For example, capillary condensation occurs in mesopores, this can be seen from the hysteresis loop on the isotherms. And in micropores, ceteris paribus, the adsorption value is greater, because due to the proximity of the pore walls relative to each other, the interaction potential with adsorbed molecules is also higher. For macropores, the accuracy of determining their diameter is directly related to the accuracy of determining pressure, because their diameter corresponds to a pressure near $\mathrm{P} / \mathrm{P}_{0}=1$.

As a device for measuring sorption, a Quanta chrome NOVA 1000 e gas sorption analyzer was used. This model of the device combines both setup for preparing samples for shooting (degassing station) and a measuring part (shooting station). The degassing station is equipped with two heating shells, allowing degassing at temperatures from room temperature to $450^{\circ} \mathrm{C}$, as well as a set of additional devices for activating the surface of the sample in a gas stream - adsorbate.

When determining the adsorption of vapors and gases, it is possible to obtain information on the porosity of solids and its structure and the specific surface. Depending on the surface area of the body and its porosity, solids can absorb more or less gas. Also, the amount of gas that solids can absorb depends on the properties and nature of the gas and on the material of the body itself(Tadeu, 2019), (Fabricio, 2019), (Ohlin, 2019), (Ferreira, 2019), (Hora, 2019).

In our case, both porosity and specific surface serve as a measure of clay swelling. Therefore, only by changing the pore size can we talk about swelling or non-swell- 
ing of clays in the reservoir. It is important to determine whether kaolin clay swells in reservoir rocks located at a depth of $3 \mathrm{~km}$ when interacting with the waters of the reservoir pressure maintenance system and whether this process can be influenced.

Studies to determine the porosity of low-permeable clayish reservoirs were carried out on several samples. The first is the core of the extracted sample, the second is the core pre-saturated with fresh water, and the third is pre-saturated with weakly mineralized water of the Formation Pressure Maintenance system. The fourth core was saturated with a pre-developed surfactant solution. The composition of surfactants includes nonionic surfactants to reduce interfacial tension at the oil-water interface, and cationic surfactants to reduce clay swelling(Kuznetsova, 2018). All samples were pre-dried in the NOVA 1000 e installation at the preparation station before the start of the study.

\section{RESULTS}

Tables 1 and 2 show the results of measurements of pore sizes. From table 1 it can be seen that in a sample saturated with freshwater, the specific surface has minimal values, which means that it is under these conditions that the rock-forming minerals have the largest size. The pore size, when saturated with freshwater, is much smaller than that of dry samples.

The Cenomanian water used for the reservoir pressure maintenance system has weaker mineralization than the reservoir water of the Jurassic deposits. But the clay component of the deposits is represented mainly by kaolinite, which is considered a non-swelling clay mineral. Therefore, clay-swelling, in this case, is not taken into account. But from table 2 it can be seen that the porosity of the sample saturated with water from the RPM System has lower values than dry and slightly more than samples saturated with fresh water. Consequently, the use of low-mineralized water from the RPM System leads to the clogging of the pore channels.

At that time, in a sample saturated with the developed surfactant composition, the pore size was close to the

Table 1: The results of determining the porosity and specific surface of the samples

\begin{tabular}{|l|c|c|}
\hline \multicolumn{1}{|c|}{ Components } & $\begin{array}{c}\text { Part name / } \\
\text { Manufacturer }\end{array}$ & Rating values \\
\hline $\begin{array}{l}\text { Specific surface, } \\
\mathrm{m}^{2} / \mathrm{g}\end{array}$ & 9.881 & 7.682 \\
\hline $\begin{array}{l}\text { Pore volume, } \\
\mathrm{cm}^{3} / \mathrm{g}(\mathrm{m})\end{array}$ & 0.01 & 0.008 \\
\hline $\begin{array}{l}\text { Pore radius, } \\
\mathrm{nm}(\mathrm{r})\end{array}$ & 1.5 & 1.3 \\
\hline $\begin{array}{l}\text { Permeability } \\
\text { coefficient, } \\
\mu \mathrm{m}^{2}(\mathrm{k})\end{array}$ & 0.006 & 0.003 \\
\hline
\end{tabular}

Table 2: The results of determining the porosity and specific surface of the samples

\begin{tabular}{|l|c|c|}
\hline \multicolumn{1}{|c|}{ Components } & $\begin{array}{r}\text { Part name / } \\
\text { Manufacturer }\end{array}$ & Rating values \\
\hline $\begin{array}{l}\text { Specific surface, } \\
\mathrm{m}^{2} / \mathrm{g}\end{array}$ & 9.562 & 8.345 \\
\hline $\begin{array}{l}\text { Pore volume, } \\
\mathrm{cm}^{3} / \mathrm{g}(\mathrm{m})\end{array}$ & 0.01 & 0.009 \\
\hline $\begin{array}{l}\text { Pore radius, } \\
\mathrm{nm}(\mathrm{r})\end{array}$ & 1.5 & 1.4 \\
\hline $\begin{array}{l}\text { Permeability } \\
\operatorname{coefficient}^{2}\end{array}$ & 0.006 & 0.004 \\
$\mu \mathrm{m}^{2}(\mathrm{k})$
\end{tabular}

size of a dry sample. This can be explained by the fact that surfactants adsorbed from an aqueous solution of surfactants on the surface of clay minerals suppress their hydration and, as a result, the pore volume increases compared to samples saturated with fresh water.

According to Equation (1)., the obtained values of porosity and radii of the pore channels were converted into the permeability coefficient. The results of these calculations are shown in tables 1 and 2 .

$k=m r^{2} / 8$

As a result, according to the calculated values, it turned out that the permeability coefficient when the sample is saturated with freshwater as a result of clay hydration decreases by 2 times. But as a result of saturation with the developed surfactant solution, clay minerals do not hydrate, which is confirmed by the data on the porosity and permeability of the studied rock samples.

\section{CONCLUSION}

Thus, using non-destructive testing methods for rock samples, we were able to determine the main filtration and reservoir characteristics of the rock, such as porosity, permeability, specific surface, and also evaluate the effect of mineralization of water and surface-active substances on the state of clay minerals in polymict rock cores collectors in their natural (undisturbed) state. Studies have shown that the state of clay minerals in the reservoir is unstable. Even "non-swellable" minerals increase in volume and worsen the reservoir properties of the rock in contact with fresh or desalinated waters. It is necessary to control the porosity of low-permeability reservoirs in order to correctly select water for the reservoir pressure maintenance system, as well as reagents to prevent a decrease in porosity.

It is also shown that correctly selected surfactant compositions can block clay swelling and, accordingly increase the oil displacement coefficient, as well as the oil recovery coefficient. 


\section{REFERENCES}

1. A. N. Kuznetsova, M. K. (29 052018 Г.). Composition for displacement for injection into a clayed oil reservoir. patent 2655685 c1 ( bull. № 16).

2. A.N. Kuznetsova, M. R. (2018). IOP Conference Series: Earth and Environmental Scienc. Surfactant Solutions for Low-Permeable Polimictic Reservoir Flooding, vol. 194 Issue. 4,, стр. 042011.

3. D.V. Sun, D. T. (2018). An environmental study on reorganizing the reservoir pressure maintenance system for western Siberia oil fields. Ekoloji (Volume 27, Issue 106), 1175-1180.

4. F. Manalo, A. K.-1. (2001). 52nd Annual Technical Meeting of the Petroleum Society held in Calgary. Assessment of Porous Media Wettability Using Nuclear Magnetic Resonance. Calgary.

5. Fabricio, D. A. (2019). Development of verification standards for brinell and rockwell hardness tests. [Desen volvimento de padrões de verificação para escalasbrinell e rockwell no ensaio de dureza]. Periodico Tche Quimica, 16(31), стр. 616-621.

6. Ferreira, A. P. (2019). New voltammetric method for determination of phenanthrene in groundwater. [Novo método voltamétrico para determinação de fenantreno emágua subterrânea]. Periodico Tche Quimica(16 (33)), стр. 169-177.

7. Gimatudinov, S. (1971). Physics of the oil and gas reservoir (Nedra, Inc., 1971). Moscow: Nedra.

8. Hora, P. H. (2019). Optimization of process of adsortion of toxic metals in laboratory generated effluents through caulinite and derivatives. [Otimização de processo de adsorção de metais tóxicos em efluentes gerados em laboratório através de caulinita e derivados]. PeriodicoTcheQuimica,(16(32)), стр. 6976.

9. I.R. Raupov, G. K. (2018). Research of polymer compositions rheological properties for oil production. ActaTechnica CSAV (Ceskoslovensk Akademie Ved)(63 (3)), 493-500.

10. J. Perret, S. P. (1998). 7th International Drainage Symposium. Characterization of Solute Breakthrough and Preferential Flow in Intact Soil Columns Using X-ray CAT Scanning. Orlando: American Society of Agricultural Engineers.

11. Khanin, A. (1969). Oil and gas reservoir rocks and their study. Moscow: Nedra.
12. Khavkin, A. (2010). Nano-occurrences and nanotechnologies in oil and gas production. Research Center "Regular and Chaotic Dynamics, Institute for Computer Research.

13. Ohlin, C. (2019). Information and Communication Technology in a Global World. Research in Social Sciences and Technology, 4(2), стр. 41-57. Source: https://ressat.org/index.php/ressat/article/view/409

14. S.C. Motta Cabrera, J. B. (2008). 10th Int. Mine Water Association Congress: Mine Water and the Environment, Proceedings of IMWA 2008. Characterization of Oil Sands Tailings using Nuclear Magnetic Resonance (NMR) Technique.

15. Tadeu, P. F. (2019). ICT in a Global World. Research in Social Sciences and Technology, 4(2), (i-ii.). Source: https://ressat.org/index.php/ressat/article/ view/431

16. Volkov, V. (2001). Colloid chemistry. Surface phenomena and disperse systems. Moscow: MSTU. International Education Program

17. NeizvestnayaD.V., Kozlova N.N., N.A. Prodanova (2018) Application of CVP-Analysis at the Water Transport Organizations. Helix. 2018. Vol. 8(1). Pages 2811-2815. https://doi.org/10.29042/2018-28112815

18. Yemelyanov, V. A., Yemelyanova, N. Y., Nedelkin, A. A., Glebov, N. B., \&Tyapkin, D. A. (2019). Information system to determine the transported liquid iron weight. Paper presented at the Proceedings of the 2019 IEEE Conference of Russian Young Researchers in Electrical and Electronic Engineering, EIConRus 2019, 377-380. doi:10.1109/EIConRus.2019.8656693

19. Rahman, P. A. (2017). Analysis of the mean time to data loss of nested disk arrays RAID-01 on basis of a specialized mathematical model. IOP Conference Series: Materials Science and Engineering, 177(1). https://doi.org/10.1088/1757-899X/177/1/012088
Paper submitted: 23.12.2019.

Paper accepted: 24.01.2020.

This is an open access article distributed under the CC BY-NC-ND 4.0 terms and conditions. 